\title{
Perception of Patient Safety Among Nurses at Teaching Hospital
}

\author{
Ghada Abdelsalam Ahmed Eldeeb ${ }^{1}$, Azza Abdallha Moustafa Ghoneim², Entsar Kamel Eldesouky ${ }^{3}$ \\ ${ }^{1}$ Department of Administration Nursing, Faculty of Nursing, Menoufia University, Shebin El-Kom, Egypt \\ ${ }^{2}$ Department of Pediatric Nursing, Faculty of Nursing, Menoufia University, Shebin El-Kom, Egypt \\ ${ }^{3}$ Department of Adult Health Care Nursing, Faculty of Nursing, Menoufia University, Shebin El-Kom, Egypt
}

Email address:

ghada_nadaa@yahoo.com (G. A. A. Eldeeb), a_ghoneim@ut.edu.sa (A. A. M. Ghoneim), asemaabakera@yahoo.com (E. K. Eldesouky)

To cite this article:

Ghada Abdelsalam Ahmed Eldeeb, Azza Abdallha Moustafa Ghoneim, Entsar Kamel Eldesouky. Perception of Patient Safety Among Nurses at Teaching Hospital. American Journal of Nursing Science. Vol. 5, No. 4, 2016, pp. 122-128. doi: 10.11648/j.ajns.20160504.11

Received: May 21, 2016; Accepted: May 31, 2016; Published: June 17, 2016

\begin{abstract}
Background: All healthcare professionals are susceptible to commit adverse events. Nurses are the key to safety improvements in many aspects. Aim of this study was to investigate perception of patient safety among nurses at Shebin ElKom Teaching Hospital. The Design of this study was descriptive research design. A convenient sample of 114 nurses was selected to carry out this study. Setting of this study was Shebin ElKom Teaching Hospital. Tool of this study was Nurse Questionnaire [1]. Results showed that there was significant difference in the nurses' perception of work environment $(80.16 \pm$ $15.8 ; \mathrm{P}<0.000)$. The majority of nurses $(57.9 \%)$ perceived low patient safety. The majority of nurses $(63.2,52.6,57.9,57.9 \&$ 52.6) perceived never occurrence of adverse events. The majority of nurses did not formally report adverse events. Conclusion: nurses perceive negative work environment, job dissatisfaction, low patient safety and underreporting trend of the adverse events. Recommendation: Strategies for improvement should include non-punitive adverse event reporting system, develop patient safety policy and set clear guidelines for improving the work environment dimensions.
\end{abstract}

Keywords: Adverse Events, Patient Safety, Work Environment, Perception

\section{Introduction}

Health-care outcomes have significantly improved with the modern scientific discoveries. However, studies from a many of countries show that with these benefits come significant risks to patient safety Hospitalized patients are at risk of suffering from adverse events, and patients on medication have the risk of medication errors and adverse reactions [2].

Research confirms that most patient harm caused by care provided by health care teams comprised of competent, wellintentioned individual practitioners. Most practitioners are already trying to do the right thing to prevent errors; the old strategy of punishing practitioners when things go wrong is unlikely to be effective for improving patient safety [3].

Patient safety refers to the reduction of risk of unnecessary harm associated with healthcare to an acceptable minimum. An acceptable minimum means the collective notions of given current knowledge, resources available and the context in which care was delivered weighed against the risk of non- treatment or other treatment [4]. Patient safety is the reduction and mitigation of unsafe acts within the healthcare system, as well as using best practices shown to lead to optimal patient outcomes [5].

Adverse events are medical errors that health care facilities could avoid. These errors called Serious Reportable Events and may result in patient death or serious disability. Most common causes of adverse events include failures in communication during handoffs, unclear communication in critical situations, lack of protocols, lack of knowledge of products or unavailability of equipment, and ineffective education [6]. Most common causes of adverse events include failure in technical performance $(35 \%)$; failure to act appropriately on available information (16\%); failure to arrange for an investigation, a procedure or a consultation (12\%); and lack of care and attention to the patient (11\%) [7].

Patient safety is the forefront of health care and quality. 
Every point in the process of care giving may contain a certain degree of inherent unsafely. Adverse events may be due to problems in practice, products, procedures, or systems. Patient safety improvements demand a complex system-wide effort, involving a wide range of actions in performance improvement, environmental safety and risk management, including infection control, safe use of medicines, equipment safety, safe clinical practice, and safe environment of care [8].

The frequencies of adverse events in hospitals vary from 3 percent to 20 percent of hospital admissions, in part because there is no optimal method for measuring incidence [9]. A recent systematic review on adverse events in USA, UK, Australia, Canada, and New Zealand revealed that the incidence rate of adverse events is $9.2 \%$ with preventability rate $43.5 \%$. The estimated cost of adverse events in USA is\$US8 to \$US14.5 billion [10].

Strategies to reduce or prevent adverse events include assessing the desirability and feasibility of a national body to lead patient safety efforts. In addition, hospitals should implement evidence-based guidelines to reduce the incidence of adverse events, establishing methods for measuring the incidence of adverse events, expanding the use of electronic health records within and between hospitals. Moreover, improving communication and continuity of care improving the utility of adverse event reporting [9].

\section{Significance of the Study}

Patient safety is the cornerstone of high-quality health care. According to WHO studies, show that about $10 \%$ of hospital patients suffer an adverse event. The incidence of in developing countries is higher than $10 \%$. Moreover, $10 \%$ of all patients admitted to hospital will unintentionally harmed. There are more deaths annually because of health care than from road accidents, breast cancer and AIDS combined [11].

Recent financial estimates suggest that adverse events cost the UK $£ 2$ billion in 2000 in extra hospital days alone and $£ 400$ million in paid negligence claims. Other costs, such as suffering of patients, their families and the health care workers involved, are incalculable [12]. Nurses are critical to reduce adverse outcomes. There are no studies on patient safety in Shebin ElKom teaching hospital hospitals. The aim of this study was to investigate nurse's perceptions of patient safety among nurses at Shebin ElKom teaching.

\section{Subjects and Methods}

\subsection{Aim of the Study}

The aim of this study was to investigate nurse's perceptions of patient safety at Shebin ElKom Teaching Hospital.

\subsection{Research Question}

What is the nurse's perception about patient safety at Shebin ElKom Teaching Hospital?

\subsection{Operational Definitions}

i. Nurses: was operationally defined in this study as a clinical nurse specialists who work in at Shebin ElKom teaching hospital in one range of specialties, such as ICU, NICU, PICU, OR, ER, obstetric department and surgical department.

ii. Perception: was defined as how nurses' perceive (beliefs and attitudes) the importance of patient safety in their clinical setting.

\subsection{Research Design}

Descriptive research design was utilized to carry out the current study.

\subsection{Research Setting}

The study was conducted at Shebin ElKom Teaching Hospital, Menoufyia Governerate, Eygpt. The hospital is affiliated to ministry of health. It has three buildings one for providing free treatments, economical building and hemodialysis building. The study included nurses from general departments and specialty units in the free part of the hospital.

\subsection{Subjects}

A convenient sample of 114 staff nurses from different departments of hospital ICU, NICU, PICU, OR, ER, obstetric department and surgical department at Shebin ElKom teaching hospital was recruited. The inclusion criterion is to have at least one year of experience in the unit.

\subsection{Instruments of the Study}

Two tools of data collection are used in this study.

i. Tool one: it includes socio-demographic characteristics of the study subjects, nurses satisfaction about their job, attendance of workshops during last year, and types of workshops.

ii. Tool two: Nurse Questionnaire likert scale adopted from Kirwan M. (2012) [12]. It includes the following parts:

a. Part one: this part assess the nurse's work environment. It consists of 32 items distributed on 6 work environment sub scale which are: staffing and resource adequacy (4 items), nurse leadership (4 items), nurse physician relationship (3 items), additional physician related items (4 items), nursing foundation for quality of care ( 9 items), nurse participation in hospital affairs ( 8 items). The response for the items of these domains was on 4point likert scale ranging from strongly disagree (1) to- strongly agree (4).

- Scoring system for this part: work environment is considered positive when the total score is $\geq 96$ and work environment is considered negative when the total score is $<96$.

b. Part two: this part assess patient safety. It consists 
of 9 items. The response for these items was on 5 point Likert scale ranging from strongly disagree (1) to strongly agree (5). The level of patient safety considered high if total score ranges from 36 to 45 . Moderate level of patient safety if the total score ranges from 27 to 35 . Low level of patient safety if the score is less than 27.

c. Part three: It include 10 items to assess frequency of adverse event occurrence (medication error; bed sore; patient fall; hospital-acquired infection; verbal abuse toward nurse; and work related physical injury to nurses), items to assess the frequency of adverse event reporting and items to assess the number of formal reported adverse events.

d. Part four: it includes 10 items to assess the frequency of tasks performed during the last work shift and 13 items to assess the important activities that nurses cannot perform during the last work shift due to time shortage.

\subsection{Procedure}

This study was conducted during the period starting from May 2015-to August 2015. An official permission to carry out the study was obtained from the responsible authorities, faculty of Nursing, Menoufia University, by the researcher to administrative staff and director of hospital of at Shebin ElKom teaching hospital. The data was collected to conduct the study after an explanation of the purpose of the study. Oral consent was obtained from the nurses to participate in the study. The researchers initially introduced themselves to all participants and then they clarified the aim of the study. Each participant notified about the right to refuse to participate in the study, before taking her verbal consent. In addition, they assured the confidentiality of information.

\subsection{Pilot Study}

It was conducted on $10 \%$ of the study sample to testing clarity of the questionnaire. It was not included in the sample to ensure stability of the answers.

\subsection{Analysis of the Results}

The data were collected and tabulated into the personal computer. Statistical analysis was done using Statistical Package for Social Science (SPSS/version 20). Quantitative data were expressed as mean \& standard deviation $(\mathrm{X} \pm \mathrm{SD})$. Qualitative data were expressed as number and percentage. P-value at 0.05 was used to determine level of significance.

\section{Results}

Figure 1 clarifies distribution of nurses according to their department. It was clear that the higher percentage of nurses was selected from pediatric intensive care unit and obstetric unit.

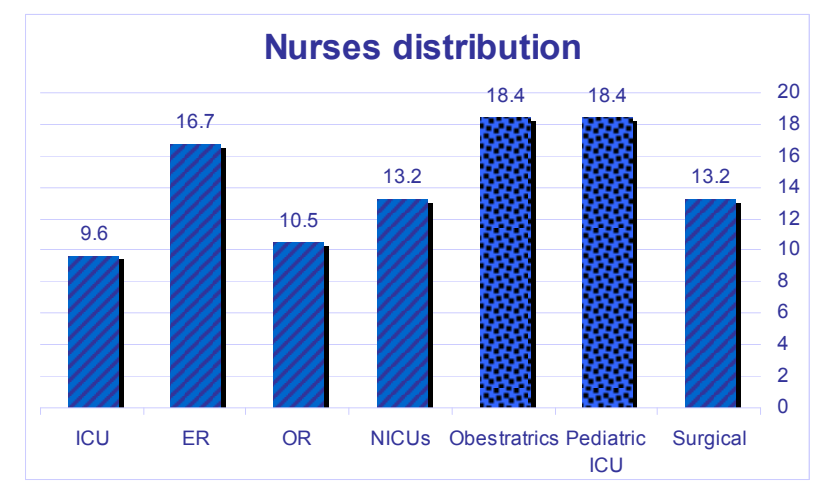

Figure 1. Distribution of nurses according to department.

Table 1. Distribution of nurses according to their Sociodemographic characteristics.

\begin{tabular}{llll}
\hline Characteristics & No & \% & Mean \pm SD \\
\hline Age & & & \\
$<30$ & 54 & 47.4 & $32.6 \pm 10.4$ \\
$30-40$ & 42 & 36.8 & \\
$>40$ & 18 & 15.8 & \\
Years of experience: & & & \\
$\leq 5$ & 33 & 28.9 & $13.1 \pm 9.7$ \\
$6-10$ & 33 & 28.9 & \\
$>10$ & 48 & 42.2 & \\
Attendance of workshops & & & \\
Yes & 75 & 65.8 & \\
No & 39 & 34.2 & \\
\hline
\end{tabular}

Table 1 shows distribution of nurses according to their sociodemographic characteristics. As indicated in the table, near half of nurses' age $(47.4 \%)$ were less than 30 years, with mean age of $32.6 \pm 9.7$ years. More than one third of nurses $(42.2 \%)$ had more than 10 years of experience. In addition, more than half of nurses $(65.8 \%)$ attended workshops during last year.

\section{Nurses qualifications}
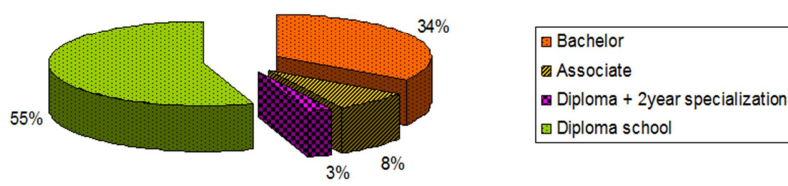

Figure 2. Distribution of nurses according to their qualifications

Figure 2 shows the distribution of nurses according to their qualifications. It revealed that more than half of nurses $(55.3 \%)$ had diploma school qualification meanwhile; about one third of nurses (34\%) had bachelor degree.

Satisfaction with nursing as a job

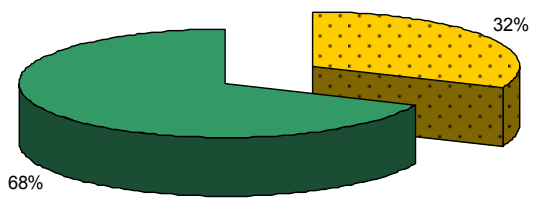
$\square$ Dissatisfied

Figure 3. Nurses' satisfaction with nursing as a job. 
Figure 3 shows nurses' satisfaction with nursing as a job. It was clear that more than half of nurses $(68.5 \%)$ were dissatisfied with nursing as a job.

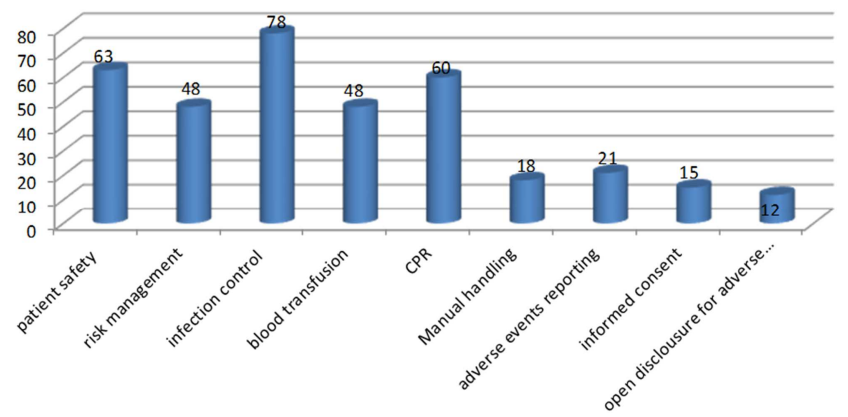

Figure 4. Types of workshops that study subjects attended during last year.

Figure 4 clarifies types of workshops that study subjects attended during the last year. It was obvious that the majority of nurses (78\%) attended infection control workshops followed by patient safety $(63 \%)$ and cardiopulmonary resuscitation $(60 \%)$ workshops.

Table 2. Nurses' perception regarding their work environment.

\begin{tabular}{llll}
\hline Work environment & No & \% & t-test p \\
\hline Positive Work environment $(\geq 96)$ & 15 & 13.2 & $54.20 .000^{* *}$ \\
Negative Work environment $(<96)$ & 99 & 86.8 & \\
Mean \pm SD & $80.16 \pm 15.8$ & \\
\hline
\end{tabular}

Table 2 illustrates nurse's perception regarding their work environment. It revealed that the majority of nurses $(86.8 \%)$ had a negative perception regarding their work environment. There was statistical significant difference between nurses regarding their perception to work environment.

Table 3. Mean scores of the characteristics of work environment subscale.

\begin{tabular}{lllll}
\hline Work environment subscale & Mean & SD & t-test & P-value \\
\hline Staffing and resource adequacy. & $(9.1)$ & 2.5 & 39.6 & $0.000^{* *}$ \\
$\begin{array}{l}\text { Nurse physician relationship. } \\
\text { Nurse leadership. }\end{array}$ & $(8.8)$ & 1.7 & 55.3 & $0.000^{* *}$ \\
$\begin{array}{l}\text { Additional physician related items. } \\
\begin{array}{l}\text { Nursing foundation for quality of } \\
\text { care. }\end{array}\end{array}$ & $(10.9)$ & 2.6 & 44.7 & $0.000^{* *}$ \\
$\begin{array}{l}\text { Nurse participation in hospital } \\
\text { affairs. }\end{array}$ & $(18.3)$ & 18.3 & 58.1 & $0.000^{* *}$ \\
\hline
\end{tabular}

Table 3 illustrates Mean scores of the characteristics of work environment subscale. It revealed that there were statistical significant differences between nurses regarding the characteristics of their work environment.

Table 4. Level of patient safety as perceived by nurses.

\begin{tabular}{llll}
\hline Level of patient safety & No. & $\%$ & Mean t-test p-value \\
\hline High $(36-45)$ & 6 & 5.3 & \\
Moderate $(27-35)$ & 42 & 36.8 & $27.259 .0980 .000 * *$ \\
Low $(<27)$ & 66 & 57.9 & \\
\hline
\end{tabular}

Table 4 shows the level of patient safety as perceived by nurses. It clarified that more than half of nurses $(57.9 \%)$ perceived low level of patient safety. Therefore, there were statistical significant differences between nurses regarding their perception of patient safety.

Table 5. Frequency of adverse event occurrence.

\begin{tabular}{|c|c|c|c|c|c|c|c|c|c|c|c|c|c|c|c|}
\hline \multirow{2}{*}{ Adverse events } & \multicolumn{2}{|c|}{ Never } & \multicolumn{2}{|c|}{ Few times/year } & \multicolumn{2}{|c|}{ Once/month } & \multicolumn{2}{|c|}{ Few times/Month } & \multicolumn{2}{|c|}{ Once/week } & \multicolumn{2}{|c|}{ Few times/week } & \multicolumn{2}{|c|}{ Every day } & \multirow[t]{2}{*}{ Total } \\
\hline & No & $\%$ & No & $\%$ & No & $\%$ & No & $\%$ & No & $\%$ & No & $\%$ & No & $\%$ & \\
\hline $\begin{array}{l}\text { Patient receives wrong } \\
\text { type of medication. }\end{array}$ & 72 & 63.2 & 39 & 34.2 & 3 & 2.6 & 0 & 0 & 0 & 0 & 0 & 0 & 0 & 0 & 114 \\
\hline $\begin{array}{l}\text { Patient receives wrong } \\
\text { dose of medication. }\end{array}$ & 60 & 52.6 & 45 & 39.5 & 9 & 7.9 & 0 & 0 & 0 & 0 & 0 & 0 & 0 & 0 & 114 \\
\hline $\begin{array}{l}\text { Patient not receives } \\
\text { medication on time. }\end{array}$ & 66 & 57.9 & 36 & 31.6 & 12 & 10.5 & 0 & 0 & 0 & & 0 & & 0 & 0 & 114 \\
\hline $\begin{array}{l}\text { Pressure ulcer after } \\
\text { admission. }\end{array}$ & 69 & 60.5 & 27 & 23.7 & 15 & 13.2 & 3 & 2.6 & 0 & 0 & 0 & 0 & 0 & 0 & 114 \\
\hline Patient fall with injury. & 66 & 57.9 & 33 & 28.9 & 12 & 10.5 & 0 & 0 & 0 & 0 & 3 & 2.6 & 0 & 0 & 114 \\
\hline $\begin{array}{l}\text { Health care associated } \\
\text { infection. }\end{array}$ & 60 & 52.6 & 39 & 34.2 & 6 & 5.6 & 3 & 2.6 & 3 & 2.6 & 3 & 2.6 & 0 & 0 & 114 \\
\hline $\begin{array}{l}\text { Patient or family } \\
\text { complaint. } \\
\text { Verbal abuse toward } \\
\text { nurses }\end{array}$ & 12 & 10.5 & 48 & 42.1 & 15 & 13.2 & 9 & 7.9 & 0 & 0 & 0 & 0 & 30 & 26.3 & 114 \\
\hline By patient or family. & 15 & 13.2 & 24 & 21.1 & 15 & 13.2 & 9 & 7.9 & 12 & 10.5 & 9 & 7.9 & 30 & 26.3 & 114 \\
\hline By other staff & 18 & 15.8 & 24 & 21.1 & 12 & 10.5 & 9 & 7.9 & 12 & 10.5 & 9 & 7.9 & 30 & 26.3 & 114 \\
\hline $\begin{array}{l}\text { Work related Physical } \\
\text { injuries to nurses }\end{array}$ & 0 & 0 & 51 & 44.7 & 15 & 13.2 & 12 & 10.5 & 9 & 7.8 & 9 & 7.8 & 18 & 15.8 & 114 \\
\hline
\end{tabular}

Table 5 shows the frequency of adverse event occurrence as perceived by nurses. It clarified that the majority of nurses (63.2, 52.6, 57.9, $57.9 \& 52.6)$ reported never occurrence of adverse events as patient receives wrong type of medication, wrong dose of medication, patient not receives medication on time, pressure ulcer after admission, patient fall with injury and health care associated infection, respectively. However, more than one third of nurses (44.7) reported that nurses have work related physical injuries few times per year. 
Table 6. Nurses' perception of adverse event reporting status.

\begin{tabular}{lll}
\hline Status of Adverse event & No. & $\mathbf{\%}$ \\
\hline $\begin{array}{l}\text { If mistake is made but caught and corrected } \\
\text { before affecting the patient }\end{array}$ & & \\
Not reported & 72 & 63.2 \\
Some times reported & 27 & 23.7 \\
Reported & 15 & 13.2 \\
If mistake is made but there is no any potential to & & \\
harm the patient & & \\
Not reported & 78 & 68.4 \\
Some times reported & 18 & 15.8 \\
Reported & 18 & 15.8 \\
If mistake is made and it could harm the patient & & \\
but it doesn't & & \\
Not reported & 69 & 60.5 \\
Some times reported & 15 & 13.2 \\
Reported & 30 & 26.3 \\
\hline
\end{tabular}

Table 6 illustrates the frequency of adverse event formal reporting. It was clear that more than half of nurses (68.4, $63.2 \& 60.5$ respectively) did not formally report adverse events whether a mistake made but there is no any potential to harm the patient or a mistake caught and corrected before affecting the patient even if the mistake could harm the patient.

Table 7. Frequency of formal reporting of adverse events for blood transfusion and risk management during last year.

\begin{tabular}{lll}
\hline Frequency of Adverse event reporting & \multicolumn{2}{l}{ Study subjects $(\mathbf{N}=\mathbf{1 1 4})$} \\
\hline blood transfusion & No. & $\mathbf{\%}$ \\
\hline 0 & 99 & 86.8 \\
2 & 3 & 2.6 \\
4 & 9 & 7.9 \\
10 & 3 & 2.6 \\
Risk management. & & \\
0 & 96 & 84.2 \\
1 & 3 & 2.6 \\
2 & 3 & 2.6 \\
3 & 3 & 2.6 \\
6 & 6 & 5.3 \\
50 & 3 & 2.6 \\
\hline
\end{tabular}

Table 7 shows the frequency of adverse event formal reporting on blood transfusion and risk management during last year. It clarified that most of nurses $(86.8 \%$ and $84.2 \%)$ reported zero blood transfusion adverse events and risk management of adverse events during the last year.

\section{Discussion}

All healthcare professionals are susceptible to commit adverse events. Nurses are the key to safety improvements in many aspects [13]. Nurses as healthcare providers believe that patient safety is primarily a nursing responsibility [14]; [15].

Regarding adverse events, the present study revealed that more than half of nurses $(68.4 \%, 63.2 \% \& 60.5 \%)$ do not formally report adverse events whether a mistake is made but there is no any potential to harm the patient or a mistake caught and corrected before affecting the patient even if the mistake could harm the patient respectively. Inconsistently, Ross reported that nurses discovered more than $90 \%$ of potential medication errors prior to administration [16].
Perhaps, fear of punishment and nurses' educational level in the current study is the cause. More than half of nurses $(55.3 \%)$ had diploma school qualification. Educational background is a significant predictor of the provided care and has a positive impact on patient safety outcomes [17, 18].

On the other hand, the findings of the current study are congruent with a Saudi Arabia study, which revealed that $58 \%$ of nurses reported mistakes and correct them before affecting the patient. Meanwhile, $55.3 \%$ of nurses reported a mistake when it is made and no potential to harm the patient and $68.1 \%$ reported a mistake when it is made and could harm the patient but does not [19].

This reflects the trend of underreporting errors by nurses. It is consistent with the finding whereby nurses reported that patients never receive wrong type of medication or wrong dose of medication nor receive medication at wrong time and zero blood transfusion adverse events and risk management of adverse events during the last year. Furthermore, error underreporting is a quandary for patient safety issue which is confirmed in several studies [20, 21, 22, 23, 24].

One of the frustrating results of the current study was related to nurse's perception of their work environment. The majority of nurses (86.8\%) had a negative perception regarding their work environment. It reflects a fact that there is a significant lack in staffing and resource adequacy, poor nurse leadership, nurse physician relationship, additional physician related items, inadequate nursing foundation for quality of care and nurse participation in hospital affairs. These findings come in agreement with Alahmadi; El-Jardali et al., who reported that shortage of nursing staff leads to an increase in workload, and this pressure is considered a major cause of errors [25, 26].

Furthermore, the nursing environment which include arrangement of nursing units, technological equipment, communication, knowledge transfer among staff, inadequate policies, fatigue, stress and workload are significant factors affecting patient safety and the quality of care $[19,27,16$, 28]. Finally, in a supportive and collaborative environment, nurses complied with the safety requirements [29].

Concerning patient safety, the current study revealed that more than half of nurses $(57.9 \%)$ perceived low level of patient safety. This could be related to negative perception of work environment reported by nurses in this study. Consistently, positive work environment, managerial commitment, nurse education level and identifying reported mistakes [31] have a positive impact on patient safety outcomes [13, 30, 31]. In addition, Ammouri et al. (2014), who reported that nurses who perceived more supervisor/manager expectations, more feedback and communications about error, more teamwork across hospital units, and more hospital handoffs and transitions had more overall perception of patient safety [32].

On the other hand, evidence support a strong causal relationship between job satisfaction, patient safety and quality of care. The current study revealed that more than half $(68 \%)$ of nurses were dissatisfied with nursing as a job. This supports the finding related to nurses' perception of low patient safety. Atefi et al. (2014) identified three main themes that influenced 
nurses' job satisfaction and dissatisfaction: spiritual feeling, work environment factors, and motivation. They concluded that Nurse Managers should ensure a flexible practice environment with adequate staffing and resources in order to improve quality of care and patient safety [33].

\section{Conclusion}

The current study concluded that nurses perceive negative work environment, job dissatisfaction, low patient safety and underreporting trend of the adverse events.

\section{Recommendations}

Based on the findings of the current study, the following recommendations are suggested:

a. Establish a non-punitive adverse event reporting system.

b. Develop patient safety policy.

c. Set clear guidelines for improving the work environment dimensions.

d. Integrate patient safety and quality improvement issues into the curriculum for undergraduate student at nursing school.

e. Develop and implement ongoing training workshops on patient safety for nurses at shebin elkom teaching hospital.

f. Further study should be conducted based on more randomized sampling process to ensure generalizability of the results.

\section{References}

[1] Kirwan M. (2012). Advancing safety in Irish hospitals: A quantitative study of organizational, ward and nurse factors that impact on patient safety outcomes. A thesis presented to Dublin City University for the degree of Doctor of Philosophy.

[2] WHO (2011). Patient Safety Curriculum Guide: Multi Professional Edition.

[3] Wallis K. \& Dovey S. (2011). Assessing Patient Safety Culture In New Zealand Primary Care: a pilot study using Manchester patient safety frame work. J prim Health care 3 (1): 35-40

[4] WHO. (2014). Patient Safety. WHO Regional Office for Europe.

[5] Canadian Patient safety institute. (2012). What is quality and patient safety? www. Patient safety institute. $\mathrm{Ca}$.

[6] Washington State Department of health (2014). Adverse events. Www.Wsna.org/topics/patient-safety/adverse events.

[7] Neal G., Woloshynowych M. \&Vincent C. (2001). Exploring the causes of adverse events in NHS Hospital practice.

[8] Xuanyue M., Yanli N., Hao C., Pengli J. and Mingming Z. (2013). Literature review regarding patient safety culture. Journal of Evidence-Based Medicine Volume 6, Issue 1, pages $43-49$.
[9] Levinson D. (2008). Adverse Events In Hospitals: Overview Of Key Issues. Department of Health and Human Services Office Of Inspector General. http://oig.hhs.gov.

[10] Allen S. (2009). Developing a safety culture: the unintended consequences of a "one size fits all" policy. Thesis. Faculty of nursing, midwifery and health. University of technology. Sydney.

[11] WHO (2012). Fundamentals of Patient Safety. http://www.who.int/patientsafety/education/curriculum/course 1_handout.pdf.

[12] NHS. (2012). What is patient safety? Scotland Quality Improvement Hub. qihub.scotland@nhs.net.

[13] Richardson, A. \& Storr, J. (2010) Patient safety: a literative review on the impact of nursing empowerment, leadership and collaboration [corrected] [published erratum appears in INT NURS REV 2010 Mar; 57 (1): 158]. International Nursing Review, 57, 12-21.

[14] Abdou, H. A. \& Saber, K. M. (2011) A baseline assessment of patient safety culture among nurses at Student University Hospital. World Journal of Medical Sciences, 6, 17-26.

[15] Aboshaiqah, A. E. (2010) Patients safety culture: A baseline assessment of nurses' perceptions in a Saudi Arabia hospital. Unpublished dissertation, Wayne State University. Available at: $\mathrm{http}$ //digitalcommons.wayne.edu/oa_dissertations/71(accesse d 30 March 2014).

[16] Ross, J. (2011) Understanding patient safety culture: part I. Journal of Perianesthesia Nursing, 26, 170-172.

[17] Idvall E, Berg A, Suhonen R, et al. Nurses' sociodemographic background and assessments of individualized care [published online ahead of print August 7, 2012]. J Nurs Scholarsh. 2012; 44 (3): 284-293.

[18] Kirwan, M., Matthews, A. \& Scott, P. A. (2013) The impact of the work environment of nurses on patient safety outcomes: a multi-level modelling approach. International Journal of Nursing Studies, 50 (2), 253-263.

[19] Aboshaiqah, A. E. \& Baker, O. G. (2013) Assessment of nurses' perceptions of patient safety culture in a Saudi Arabia hospital. Journal of Nursing Care Quality, 28, 272-280.

[20] Liu Y, Kalisch B, Zhang L. Perception of safety culture by nurses in hospitals in China. J Nurs Care Qual. 2009; 24 (1): 63-68.

[21] Ahmad NG, Samia MA, Iman IA. Patient safety: assessing nurses' perception and developing an improvement plan. Life Sci J. 2011; 8 (2): 53-64.

[22] Bodur S, Filiz E. Validity and reliability of Turkish version of "Hospital Survey on Patient Safety Culture"and perception of patient safety in public hospitals in Turkey. BMC Health Serv Res. 2010; 10: 28. doi: 10.1186/1472-6963-10-28

[23] Blegen MA, Vaughn T, Pepper G, et al. Patient and staff safety: voluntary reporting. Am J Med Qual. 2004; 19 (2): 67-74.

[24] Hughes CM, Lapane KL. Nurses' and nursing assistants' perceptions of patient safety culture in nursing homes. Int $\mathrm{J}$ Qual Health Care. 2006; 18 (4): 281-286.

[25] Alahmadi, H. A. (2010) Assessment of patient safety culture in Saudi Arabian hospitals. Quality and Safety in Health Care, $19,1-5$. 
[26] El-Jardali, F., et al. (2014) Patient safety culture in a large teaching hospital in Riyadh: baseline assessment, comparative analysis and opportunities for improvement. BMC Health Services Research, 14, 122.

[27] Keller, S. M. (2009) Effects of extended work shifts and shift work on patient safety, productivity, and employee health. AAOHN Journal: Official Journal of the American Association of Occupational Health Nurses, 57, 497-502.

[28] Zakari, N. (2011) Attitude of academic ambulatory nurses toward patient safety culture in Saudi Arabia. Life Science Journal, 8, 230-237.

[29] Singer, S., et al. (2009) Relationship of safety climate and safety performance in hospitals. Health Services Research, 44, $399-421$.
[30] Hughes, L. C., Chang, Y. \& Mark, B. A. (2009) Quality and strength of patient safety climate on medical-surgical units. Health Care Management Review, 34 (1), 19-28.

[31] Scherer, D. \& Fitzpatrick, J. J. (2008) Perceptions of patient safety culture among physicians and RNs in the perioperative area. AORN Journal, 87 (1), 163-175.

[32] Ammouri AA, Tailakh AK, Muliira RNMA, Geethakrishnan and Al Kindi SN (2014). Patient safety culture among nurses. International Nursing Review, Volume 62, Issue 1, pages 102110 .

[33] Atefi, N; Abdullah, K. L; Wong, L. P \& Mazlom, R. Factors influencing registered nurses perception of their overall job satisfaction: a qualitative study. International Nursing Review. 61 (3): 352-360, September 2014. 